\title{
Analisis Perbandingan Efisiensi Biaya Dan Metode Pelaksanaan Konstruksi Jalan Aspal Beton Dengan Rigid Beton
}

\author{
Jacob Bokko *, Parea Rusan Rangan** \\ * Prodi Teknik Sipil,Fakultas Teknik, Universitas Kristen Indonesia Toraja
}

\begin{abstract}
Penelitian ini akan membandingkan kedua kontruksi perkerasan dari segi biaya, dan metode pelaksanaan. Aspek biaya merupakan salah satu hal yang mempengaruhi pelaksanaan proyek kontruksi jalan. Oleh sebab itu perlu adanya perencanaan biaya yang baik agar tidak terjadi pemborosan. Perbandingan biaya kontruksi difokuskan pada biaya lapis permukaan dan leveling sepanjang $2.500 \mathrm{~m}$ antara aspal beton dengan rigid beton.

Metode penelitian dibagi dalam 3 (tiga) tahap yaitu tahap pertama adalah studi pustaka dan survey awal, tahap kedua adalah pengumpulan data sekunder, dan tahap ketiga adalah analisa hasil dan kesimpulan saran.

Hasil analisis biaya masing - masing kontruksi di atas untuk rigid beton sebesar Rp. 1.713.571.000,00 dan untuk aspal beton sebesar Rp. 2.994.474.000,00. Dengan kelebihan biaya sebesar Rp. 1.280.903.000.00 dari biaya aspal beton dengan nilai Rp. 2.994.474.000,00. Perbedaan dari segi metode pelaksanaan antara metode rigid beton dan metode aspal beton terdapat perbedaan yang mendasar untuk rigid beton tanpa memerlukan pemadatan sedangkan aspal beton membutuhkan proses pemadatan dengan 3 tahap yaitu pemadatan awal, pemadatan antara, pemadatan akhir. Untuk segi waktu pelaksanaan aspal beton hanya 1 bulan 2 minggu pekerjaan dibandingkan rigid beton yang lebih lama pelaksanaan pekerjaan sekitar 2 bulan 3 minggu.
\end{abstract}

Kata Kunci : Efisiensi Biaya, Metode Pelaksanaan, Aspal Beton, Rigid Beton

\section{BAB I \\ PENDAHULUAN}

\subsection{Latar Belakang}

Jalan merupakan infrastruktur dasar dan utama dalam menggerakkan roda perekonomian nasional dan daerah, mengingat penting dan strategisnya fungsi jalan untuk mendorong distribusi barang dan jasa sekaligus mobilitas penduduk. Ketersediaan jalan adalah prasyarat mutlak bagi masuknya investasi ke suatu wilayah. Jalan memungkinkan seluruh masyarakat mendapatkan akses pelayanan pendidikan, kesehatan dan pekerjaan. Untuk itu diperlukan perencanaan struktur perkerasan yang kuat, tahan lama dan mempunyai daya tahan tinggi terhadap deformasi plastis yang terjadi. 
Pada pembuatan rigid beton tegangan pada pelat beton dengan berbagai ukuran panjang akan melebihi kekuatan tarik materialnya. Oleh karena itu, retak pada pelat yang panjang pasti akan terjadi secara acak tak terkendali, tak terlihat atau pada lokasi yang memang ditetapkan sebelumnya.

Seperti kita ketahui bersama bahwa untuk membangun suatu sarana transportasi memerlukan dana yang tidak sedikit dan metode pelaksanaan yang tepat. Oleh sebab itu, diperlukan perencanaan kontruksi jalan dan perencanaan pekerjaan jalan yang optimal dan memenuhi syarat teknis menurut fungsi, volume maupun sifat lalu lintas sehingga pembangunan kontruksi tersebut dapat berguna maksimal bagi perkembangan daerah sekitarnya.

Pedoman ini merupakan pedoman yang berguna untuk pekerjaan pemeliharaan preventif atau pemeliharan priodik. Berdasarkan hal tersebut diatas, penulis tertarik mengangkat judul mengenai.

\subsection{Rumusan Masalah}

Adapun rumusan masalah yang akan dibahas dalam penelitian ini adalah:

a. Bagaimana menganalisis perbandingan efisiensi biaya konstruksi jalan aspal beton dengan rigid beton?

b. Bagaimana perbandingan metode pelaksanaan konstruksi jalan aspal beton dengan rigid beton?

\subsection{Tujuan Penelitian}

Tujuan dari penelitian ini adalah sebagai berikut:

a. Untuk mengetahui analisis perbandingan efisiensi biaya antara jalan aspal beton dan rigid beton.

b. Untuk mengetahui perbandingan metode pelaksanaan konstruksi jalan aspal beton dan rigid beton.

BAB II

\section{LANDASAN TEORI}

\subsection{Aspal}

Dalam pengertian teknik secara umum, ASPAL didefinisikan sebagai Material berwarna hitam atau coklat tua. Pada temperatur ruang berbentuk padat sampai agak padat, jika dipanaskan sampai temperatur tentu dapat menjadi lunak atau cair sehingga dapat membungkus partikel agregat pada waktu pembuatan campuran aspal beton atau saat masuk kedalam pori-pori yang ada pada penyemprotan atau penyiraman pada perkerasan macadam atau pelaburan. Jika temperatur mulai turun. Aspal akan mengeras dan mengikat agregat pada tempatnya (sifat Termoplastis).

\subsection{Beton}

Beton adalah suatu campuran yang berisi pasir (agregat halus), batu pecah (agregat kasar), agregat lain yang di campurkan menjadi satu massa yang sangat mirip seperti batu, dapat digunakan untuk pondasi, balok, plat lantai dan lain - lain. 
Pada proses terbentuknya beton, semen dan air akan membentuk pasta semen yang berfungsi sebagai perekat atau pengikat dalam proses pengerasan.

Pada proses pengerasan, pasta semen dan agregat halus (pasir) akan membentuk mortar yang akan menutup rongga-rongga antara agregat kasar (kerikil atau batu pecah) sedangkan pori-pori antara agregat halus diisi oleh pasta semen yang merupakan campuran antara semen dengan air sehingga butiran-butiran agregat saling terikat dengan kuat dan terbentuklah sautu massa yang kompak atau padat.

Struktur beton sangat dipengaruhi oleh komposisi dan kualitas bahan-bahan pencampur beton, yang dibatasi oeeh kemampuan daya tekan (in a state of copmpression) seperti yang tercantum dalam perencanaannya. Hal tersebut bergantung juga pada kemampuan daya dukung tanah (supported by soil).

\subsection{Rigid Beton}

Rigid Beton atau perkerasan beton semen adalah suatu konstruksi (perkerasan) dengan bahan baku agregat dan menggunakan semen sebagai bahan pengikatnya.

Pada saat ini dikenal ada 5 jenis perkerasan beton semen yaitu :

- Perkerasan beton semen tanpa tulangan dengan sambungan ( Jointed plain concrete pavement).

- Perkerasan beton semen bertulang dengan sambungan ( Jointed reinforced concrete pavement ).

- Perkerasan beton semen tanpa tulangan ( Continuosly reinforced concrete pavement ) .

- Perkerasan beton semen prategang ( Prestressed concrete pavement).

- Perkerasan beton semen bertulang fiber (Fiber reinforced concrete pavement ).

\subsection{Rencana Anggaran Biaya (RAB)}

\subsubsection{Pengertian Biaya Proyek dan Definisi RAB}

Secara umum biaya dalam suatu proyek dapat digolongkan menjadi:

A. Biaya Tetap ( Modal Tetap/Fixed Capital)

Merupakan bagian dari biaya proyek yang digunakan untuk menghasilkan produk yang diinginkan, mulai dari studi kelayakan sampai atau instalasi suatu proyek/pekerjaan berjalan penuh.

Dalam hal ini biaya tetap sendiri dibedakan menjadi dua, yaitu:

A.1. Biaya Langsung (Direct Cost), yaitu himpunan pengeluaran untuk tenaga kerja, bahan, alat-alat dan sub kontraktor. Apabila waktu (duration) dipercepat, maka pada umumnya biaya langsung secara total akan semakin tinggi.

A.2. Biaya Tidak Langsung (Indirect Cost), yaitu himpunan pengeluaran untuk overhead, pengawasan resiko-resiko dan lain-lain. Apabila waktu (duration) diperlambat, maka biaya tidak langsungnya akan semakin tinggi.

B. Biaya Tidak Tetap (Modal Kerja/Working Capital)

Merupakan biaya yang digunakan untuk menutupi kebutuhan pada tahap awal operasi. Dari uraian tersebut dapat digunakan untuk mendefinisikan tentang pengertian Rencana Anggaran Biaya (RAB) tersebut. Dilihat dari asal katanya yaitu : 
1. Rencana, adalah himpunan planning, termasuk detail/penjelasan dan tata cara pelaksanaan pembuatan sebuah bangunan, terdiri dari : bestek dan gambar bestek.

2. Anggaran, adalah perkiraan/perhitungan biaya suatu bangunan berdasarkan bestek dan gambar bestek.

3. Biaya, adalah besar pengeluaran yang berhubungan dengan borongan yang tercantum dalam persyaratan-persyaratan yang terlampir.

Jadi Rencana Anggaran Belanja meliputi :

- Perencanaan bentuk bangunan yang memenuhi syarat

- Perkiraan terhadap biaya yang diperlukan

- Penyusunan tata cara pelaksanaan teknis dan administrasi

Tujuan pembuatan Rencana Anggaran Belanja (RAB) adalah untuk memberikan gambaran yang pasti mengenai : bentuk/konstruksi, besar biaya dan pelaksanaan serta penyelesaian.

\subsubsection{Analisa Bahan, Upah, Alat dan Harga Satuan Pekerjaan}

a. Analisa Bahan

Analisa bahan suatu pekerjaan adalah menghitung banyaknya volume masing-masing bahan untuk setiap aktifitas, serta biaya yan dibutuhkan.

b. Analisa Upah

Menghitung banyaknya tenaga yang diperlukan untuk setiap kegiatan, serta besar biaya yang diperlukan untuk pekerjaan tersebut

c. Analisa Alat

Analisa terhadap peralatan yang dibutuhkan dalam setiap pekerjaan dalam suatu proyek dimana digunakan alat-alat yang membutuhkan biaya.

\section{d. Analisa harga Satuan Pekerjaan}

Analisa terhadap harga satuan pekerjaan merupakan penjumlahan dari harga satuan bahan dengan harga satuan upah.

$$
\text { Satuan Pekerjaan }=\text { Harga Bahan }+ \text { Upah }
$$

\subsubsection{Perhitungan RAB Secara Keseluruhan}

Pada dasarnya perhitungan RAB merupakan perhitungan biaya-biaya yang diperlukan untuk bahan dan upah tenaga kerja berdasarkan analisis tertentu dan biaya-biaya lain yang berhubungan dengan pelaksanaan pekerjaan. Dapat pula dinyatakan bahwa RAB merupakan jumlah dari masing-masing hasil perkalian Volume dan Harga Satuan Pekerjaan.

Perhitungan RAB secara keseluruhan :

$$
\mathrm{RAB}=\Sigma(\text { Volume } \mathrm{x} \text { Harga Satuan Pekerjaan })
$$

\subsection{Metode Pelaksanaan}

Pada tahap pelaksanaan suatu proyek mengacu pada perencanaan yang sudah diperhitungkan dengan matang, sehingga dalam pelaksanaan ini sebisa mungkin 
dihindari hambatan-hambatan yang dapat mengganggu kelancaran jalannya suatu proyek.

Dalam kenyataan yang ada, sering kali pelaksanaan suatu proyek tidak sesuai dengan perencanaan. Hal ini mungkin disebabkan karena adanya beberapa alasan sehingga mengakibatkan terjadinya perubahan terhadap jadwal yang sudah disusun. Dengan adanya perubahan tersebut sering kali suatu proyek mengalami percepatan dan keterlambatan dalam pelaksanaannya.

\subsubsection{Metode Pelaksanaan Aspal Beton}

1) Peralatan Pelaksanaan

2) Penyiapan Lapangan

3) Penyebaran

4) Pemadatan Lapisan Aspal

5) Penyelesaian

6) Penyelesaian sambungan

\subsubsection{Metode Pelaksanaan Rigid Beton}

1) Pekerjaan Mobilisasi

2) Pekerjaan Drainase

3) Pekerjaan Struktur

4) Campuran Adukan Beton

\section{METODOLOGI PENELITIAN}

\subsection{Gambaran Umum Lokasi Penelitian}

\section{a. Lokasi Penelitian Untuk Rigid Beton}

Lokasi pengambilan data untuk rigid beton dalam penulisan ini terletak di Lembang Sasak, Kecamatan Bittuang, Kabupaten Tana Toraja. Jarak tempuh dari Kota Makale ke Kecamatan Bittuang yaitu $\pm 56 \mathrm{~km}$. Dilokasi Lembang Sasak ada beberapa Dusun, yaitu Dusun Sasak, Dusun Luya, Dusun Rea dan Dusun Marura. Sedangkan lokasi tempat penelitian ini berada di Dusun Luya. Kecamatan Bittuang memiliki luas wilayah 163,27 m2 dengan koordinat geografis berada pada 2॰58’33” LS dan 11940’26” BT.

\section{b. Lokasi Penelitian Untuk Aspal Beton}

Lokasi pengambilan data untuk aspal beton dalam penulisan ini terletak di Lembang tondon, Kecamatan Tondon, Kabupaten Toraja Utara. Jarak tempuh dari Kota Rantepao ke Kecamatan tondon yaitu $\pm 2 \mathrm{~km}$. Sedangkan lokasi tempat penelitian ini berada di Panga'

\subsection{Tahap dan Prosedur Penelitian}

Sebagai penelitian ilmiah maka penelitian harus dilaksanakan dalam sistematika atau urutan kerja yang jelas dan teratur sehingga akan didapat hasil yang baik dan dapat dipertanggung jawabkan. Pelaksanaan penelitian ini dibagi menjadi tahap-tahap sebagai berikut : 


\section{a. Persiapan}

Sebelum melaksanakan pengambilan data secara lengkap diperlukan survey awal lokasi yang akan dijadikan tempat pengambilan data sebagai bahan pertimbangan awal untuk langkah selanjutnya.

\section{b. Pengambilan Data}

Data merupakan faktor yang berpengaruh dan sangat diperlukan untuk meganalisa permasalahan yang akan dibahas. Data yang dimaksud adalah data mengenai aspal beton yang dilaksanakan di Lembang Sasak, Kecamatan Bittuang dan data mengenai rigid beton yang dilaksanakan di Lembang Tondon (Panga'), Kecamatan Tondon. Jenis-jenis data tersebut antara lain adalah:

1) Data Primer ( volume pekerjaan)

2) Data Sekunder (gambar pelaksanaan pekerjaan, anggaran biaya, metode pelaksanaaan dan waktu pelaksanaan)

\section{c. Pengolahan Data}

Pengolahan Data dilaksanakan berdasarkan dengan data primer (volume pekerjaan) yang diperoleh dari lapangan dan didukung oleh data sekunder (gambar pelaksanaan pekerjaan, anggaran biaya, metode pelaksanaaan dan waktu pelaksanaan).

\section{d. Analisa dan Pembahasan}

Membahas semua data yang sudah dianalisis dengan menguraikan secara rinci tentang hasil penelitian yang akan mengarah kesimpulan yang terkait dengan tujuan penelitian.

\section{e. Kesimpulan dan Saran}

Bagian ini memuat pernyataan singkat dan tepat mengenai hasil dari pembahasan. Kesimpulan merupakan rekapitulasi atau rangkuman dari butir-butir pemikiran utama peneliti yang mencerminkan nilai penelitian dan pemahaman peneliti tentang apa yang dilaporkan. 


\subsection{Bagan Alir Penelitian}

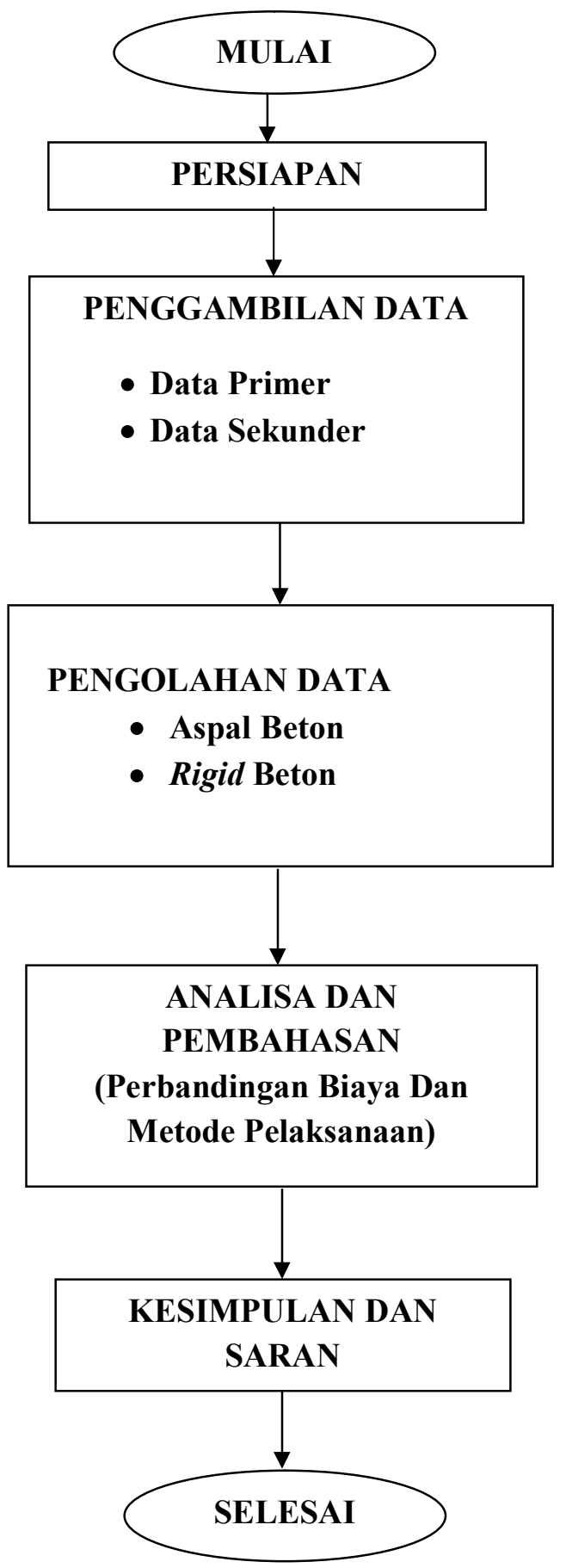




\subsection{Metode Pengambilan Data}

Pengambilan data merupakan sarana pokok untuk menemukan suatu penyelesaiaan masalah secara ilmiah. Dalam pengambilan data, peranan instansi terkait sangat diperlukan sebagai pendukung dalam memperoleh data-data yang diperlukan.

Hal-hal yang perlu diperhatikan dalam pengambilan data adalah:

1. Jenis data

2. Tempat diperolehnya data.

3. Jumlah data yang harus dikumpulkan agar diperoleh data yang memadai.

\section{Data Primer}

Data primer adalah data yang akan diperoleh lansung dari lapangan. Data primer yang dimaksud yaitu:

a. Data rigid beton (volume pekerjaan).

Tabel 3.1 Data Primer Rigid Beton

\begin{tabular}{|l|c|c|c|}
\hline \multirow{2}{*}{ Rigid beton } & Panjang $(\mathrm{km})$ & Lebar $(\mathrm{m})$ & Tebal $(\mathrm{m})$ \\
\cline { 2 - 4 } & 2,5 & 4 & 0,15 \\
\hline
\end{tabular}

Sumber: Hasil Pengambilan Data Lapangan 2016

b. Data aspal beton (volume pekerjaan).

Tabel 3.2 Data Primer Aspal Beton

\begin{tabular}{|c|c|c|}
\hline \multirow{2}{*}{ Aspal beton } & Panjang $(\mathrm{km})$ & Lebar $(\mathrm{m})$ \\
\cline { 2 - 3 } & 3,334 & 6 \\
\hline
\end{tabular}

Sumber: Hasil Pengambilan Data Lapangan 2016

\section{Data Sekunder}

Data sekunder adalah data pendukung untuk penelitian di lapangan maupun pada saat pelaksanaan pengolahan data yang tentunya data sekunder ini diperoleh dari suatu instansi terkait. Data sekunder yang dimaksud adalah:

Data sekunder rigid beton diperoleh dari PT. Hujan Berkat adalah sebagai berikut:

- Gambar pelaksanaan pekerjaan.

- Anggaran biaya.

- Metode pelaksanaan.

- Waktu pelaksanaan (time schedule).

Sedangkan data sekunder aspal beton di peroleh dari PT. Gangking Raya adalah sebagai berikut:

- Gambar pelaksanaan pekerjaan.

- Anggaran biaya.

- Metode pelaksanaan.

- Waktu pelaksanaan (time schedule).

\subsection{Metode Analisa Data}

Analisa dan pengolahan data dilakukan berdasarkan data-data yang telah diperoleh, selanjutntya dikelompokan sesuai indetifikasi tujuan permasalahan sehingga diperoleh 
analisa pemecahan masalah yang efektif dan terarah. Data yang akan dianalisa merupakan data primer dan data sekunder yang sudah di dapatkan dari penelitian lapangan serta data dari PT. Hujan Berkat dan PT. Gangking Raya. Adapun langkahlangkah dalam penganalisaan data sebagai berikut:

a. Menghitung kembali volume data jalan rigid beton dan aspal beton karena panjang jalan yang akan di gunakan sebagi perbandingan hanya $2 \mathrm{~km}$. Adapun cara perhitugan yang digunakan untuk menghitung kebali volume pekerjaan adalah:

Dimana:

$\mathrm{V} \quad=$ volume

$\mathrm{p} \quad=$ panjang

$1=$ lebar

$\mathrm{t} \quad=$ tinggi atau tebal perkerasan jalan

b. Menghitung kembali anggaran biaya untuk rigid beton dan aspal beton sebab data yang diperoleh dari PT. Hujan Berkat dan PT. Gangking Raya masih melampirkan beberapa item pekerjaan lain serta anggaran biaya untuk perkerasan jalan belum menggunakan panjang jalan yang akan yang akan dijadikan sebagai perbandingan. Untuk menghitung kembali anggran biaya penulis menggunakan aplikasi computer yaitu Microsoft excel dengan berpedoman pada analisa harga satuan pekerjaan dan harga material yang digunakan untuk masing-masing material. Adapun cara untuk menghitung kembali anggaran biaya adalah sebagai berikut:

juml ah harga $=$ volume $x$ hargas atuan

c. Merubah metode pelaksanaan karena metode pelaksanaan yang diperoleh dari PT. Hujan Berkat dan PT. Gangking Raya sudah tidak sesuai dengan anggaran yang sudah dimodifikasi atau dirubah oleh penulis dalam rencana anggaran biaya (RAB) untuk menentukan efisisensi pelaksanaan rigid beton dan aspal beton.

d. Memperbandingkan hasil analisa biaya dan metode pelaksanaan antara jalan aspal beton dengan rigid beton yang telah dilakukan untuk mengetahui perkerasan yang lebih efisien digunakan dalam pembangunan jalan serta membandingkan waktu pelaksanaan (time schedule) yang telah diperoleh dari PT. Hujan Berkat dan PT. Gangking Raya.

\section{ANALISA DAN PEMBAHASAN}

\subsection{Hasil Perhitungan Biaya Pekerjaan Jalan Aspal Beton Dan Rigid Beton}

Perhitungan anggaran biaya dimaksudkan untuk membandingakan biaya antara aspal beton dengan rigid beton.

\subsubsection{Perhitungan Volume Pekerjaan Jalan Aspal Beton Dan Rigid Beton}

a. Aspal Beton

Sebagai hasil dari pembahasan dilakukan perhitungan volume aspal beton dengan panjang 2,5 $\mathrm{km}$ dan lebar $4 \mathrm{~m}$ dimulai dari sta $0+000$ sampai dengan sta $2+500$ yang dapat dilihat pada tabel berikut: 
Tabel 4.1 Hasil Perhitungan Volume Pekerjaan Aspal Beton

\begin{tabular}{|c|l|c|c|}
\hline $\begin{array}{c}\text { No. Mata } \\
\text { Pembayaran }\end{array}$ & \multicolumn{1}{|c|}{ Uraian Pekerjaan } & Satuan & Volume \\
\hline 3.2.(2a) & Timbunan Pilihan Dari Sumber Galian & M3 & 112 \\
\hline 3.2.(3a) & $\begin{array}{l}\text { Timbunan Pilihan (Diukur Diatas Bak } \\
\text { Truk) }\end{array}$ & M3 & 148.37 \\
\hline 5.1.(1) & Lapis Pondasi Agregat Kelas A & M3 & 1.500 \\
\hline 5.1.(2) & Lapis Pondasi Agregat Kelas B & M3 & 2.000 \\
\hline 6.1(1)(a) & Lapis Resep Pengikat - Aspal Cair & Liter & $6.500,16$ \\
\hline 6.1(2)(a) & Lapis Perekat - Aspal Cair & Liter & $2.123,76$ \\
\hline 6.3(5a) & Laston Lapis Aus (AC-WC) & Ton & 976 \\
\hline 6.3(6a) & Laston Lapis Antara (AC - BC) & Ton & 1.349 \\
\hline
\end{tabular}

Sumber: Hasil Analisa 2017

\section{b. Rigid Beton}

Sebagai hasil dari pembahasan dilakukan perhitungan volume rigid beton dengan panjang 2,5 $\mathrm{km}$ dan lebar $4 \mathrm{~m}$ dimulai dari sta $0+000$ sampai dengan sta $2+500$ yang dapat dilihat pada tabel berikut:

Tabel 4.2 Hasil Perhitungan Volume Pekerjaan Rigid Beton

\begin{tabular}{|c|l|c|c|}
\hline $\begin{array}{c}\text { No. Mata } \\
\text { Pembayaran }\end{array}$ & \multicolumn{1}{|c|}{ Uraian Pekerjaan } & Satuan & Volume \\
\hline 3.2.(2a) & Timbunan Pilihan Dari Sumber Galian & M3 & 448,75 \\
\hline 3.2.(3a) & $\begin{array}{l}\text { Timbunan Pilihan (Diukur Diatas Bak } \\
\text { Truk) }\end{array}$ & M3 & 470,77 \\
\hline 7.1.(8) & Beton Mutu Rendah fc'15 MPa & M3 & $1.506,48$ \\
\hline
\end{tabular}

Sumber: Hasil Analisa 2017

\subsubsection{Analisa Harga Satuan}

Pada tahap ini analisa yang dilakukan antara lain kebutuhan tenaga kerja, kebutuhan bahan, dan kebutuhan peralatan untuk masing-masing pekerjaan berdasarkan data-data yang di peroleh dari PT. Gangking Raya dan PT. Hujan Berkat. Analisa harga satuan untuk aspal beton dan rigid beton, disajikan pada beberapa tabel dibawah ini:

\section{a. Aspal Beton}

Tabel 4.3 Analisa Harga Satuan Pekerjaan Aspal Beton

\begin{tabular}{|c|l|c|r|}
\hline $\begin{array}{c}\text { No. Mata } \\
\text { Pembayaran }\end{array}$ & \multicolumn{1}{|c|}{ Uraian Pekerjaan } & Satuan & $\begin{array}{c}\text { Harga Satuan } \\
\text { (Rupiah) }\end{array}$ \\
\hline 1.2 & Mobilisasi & LS & $12.950 .000,00$ \\
\hline 3.2.(2a) & Timbunan Pilihan Dari Sumber Galian & M3 & $332.928,92$ \\
\hline 3.2.(3a) & $\begin{array}{l}\text { Timbunan Pilihan (Diukur Diatas Bak } \\
\text { Truk) }\end{array}$ & M3 & $276.440,40$ \\
\hline 5.1.(1) & Lapis Pondasi Agregat Kelas A & M3 & $496.231,02$ \\
\hline 5.1.(2) & Lapis Pondasi Agregat Kelas B & M3 & $416.355,00$ \\
\hline
\end{tabular}




\begin{tabular}{|c|l|c|r|}
\hline $6.1(1)(\mathrm{a})$ & Lapis Resep Pengikat - Aspal Cair & Liter & $14.732,00$ \\
\hline $6.1(2)(\mathrm{a})$ & Lapis Perekat - Aspal Cair & Liter & $15.126,81$ \\
\hline $6.3(5 \mathrm{a})$ & Laston Lapis Aus (AC-WC) & Ton & $1.325 .215,48$ \\
\hline $6.3(6 \mathrm{a})$ & Laston Lapis Antara (AC - BC) & Ton & $1.286 .432,33$ \\
\hline
\end{tabular}

Sumber: Hasil Analisa 2017

\section{a. Rigid Beton}

Tabel 4.4 Analisa Harga Satuan Pekerjaan Rigid Beton

\begin{tabular}{|c|l|c|r|}
\hline $\begin{array}{c}\text { No. Mata } \\
\text { Pembayaran }\end{array}$ & \multicolumn{1}{|c|}{ Uraian Pekerjaan } & Satuan & $\begin{array}{c}\text { Harga Satuan } \\
\text { (Rupiah) }\end{array}$ \\
\hline 1.2 & Mobilisasi & LS & $12.000 .000,00$ \\
\hline 3.2.(2a) & Timbunan Pilihan Dari Sumber Galian & M3 & $332.928,92$ \\
\hline 3.2.(3a) & $\begin{array}{l}\text { Timbunan Pilihan (Diukur Diatas Bak } \\
\text { Truk) }\end{array}$ & M3 & $276.440,40$ \\
\hline 7.1.(8) & Beton Mutu Rendah fc'15 MPa & M3 & $1.137 .467,37$ \\
\hline
\end{tabular}

Sumber: Hasil Analisa 2017

\subsubsection{Rencana Anggaran Biaya (RAB)}

Pada tahap ini penghitungan anggaran biaya yang dilakukan untuk mengetahui kebutuhan biaya dari masing-masing pekerjaan berdasarkan data-data yang di peroleh dari data perhitungan volume dan analisa harga dari aspal beton dan rigid beton.

a. Aspal Beton

Tabel 4.14 Rencana Anggaran Biaya (RAB) Pekerjaan Aspal Beton

\begin{tabular}{|c|c|c|c|c|}
\hline No & Uraian Pekerjaan & Satuan & Volume & $\begin{array}{l}\text { Jumlah Harga } \\
\text { (Rupiah) }\end{array}$ \\
\hline 1 & Mobilisasi & LS & 1.00 & $12.950 .000,00$ \\
\hline 2 & Timbunan Pilihan Dari Sumber Galian & M3 & 112 & $37.288 .039,04$ \\
\hline 3 & $\begin{array}{c}\text { Timbunan Pilihan (Diukur Diatas Bak } \\
\text { Truk) }\end{array}$ & M3 & 148,37 & $41.015 .462,15$ \\
\hline 4 & Lapis Pondasi Agregat Kelas A & M3 & 1.500 & $703.846 .530,00$ \\
\hline 5 & Lapis Pondasi Agregat Kelas B & M3 & 2.000 & $832.710 .000,00$ \\
\hline 6 & Lapis Resep Pengikat - Aspal Cair & Liter & $6.500,16$ & $95.763 .087,19$ \\
\hline 7 & Lapis Perekat-Aspal Cair & Liter & $2.123,76$ & $32.125 .714,01$ \\
\hline 8 & Laston Lapis Aus (AC-WC) & Ton & 976 & $1.293 .410 .288,96$ \\
\hline 9 & Laston Lapis Antara $(\mathrm{AC}-\mathrm{BC})$ & Ton & 1.349 & $1.735 .397 .213,17$ \\
\hline & $\begin{array}{c}\text { Jumlah } \\
\text { PPN } 10 \% \\
\text { Jumlah Total } \\
\text { Dibulatkan }\end{array}$ & & & $\begin{array}{c}.784 .506 .334,51 \\
478.450 .663,45 \\
5.262 .956 .967,96 \\
5.262 .957 .000,00\end{array}$ \\
\hline & Tujuh Ril & upiah", & & tus Lima Puluh \\
\hline
\end{tabular}

b. Rigid Beton

Tabel 4.15 Rencana Anggaran Biaya (RAB) Pekerjaan Rigid Beton

\begin{tabular}{|c|c|c|c|c|}
\hline No. & Uraian Pekerjaan & Satuan & Volume & $\begin{array}{c}\text { Jumlah Harga } \\
\text { (Rupiah) }\end{array}$ \\
\hline 1 & Mobilisasi & LS & 1.00 & $12.000 .000,00$ \\
\hline
\end{tabular}




\begin{tabular}{|c|c|c|c|c|}
\hline 2 & $\begin{array}{c}\text { Timbunan Pilihan Dari Sumber } \\
\text { Galian }\end{array}$ & M3 & 448,75 & $149.401 .852,85$ \\
\hline 3 & $\begin{array}{c}\text { Timbunan Pilihan (Diukur Diatas } \\
\text { Bak Truk) }\end{array}$ & M3 & 470,77 & $130.139 .847,11$ \\
\hline 4 & Beton Mutu Rendah fc'15 MPa & M3 & $1.506,48$ & $1.713 .571 .843,56$ \\
\hline \multicolumn{4}{|c|}{$\begin{array}{l}\text { Jumlah } \\
\end{array}$} & $2.005 .113 .543,52$ \\
\hline \multicolumn{4}{|c|}{ PPN $10 \%$} & $200.511 .354,35$ \\
\hline \multicolumn{4}{|c|}{ Jumlah Total } & 2.205.624.897,87 \\
\hline \multicolumn{4}{|c|}{ Dibulatkan } & $2.205 .625 .000,00$ \\
\hline
\end{tabular}

Sumber: Hasil Analisa 2017

\subsubsection{Analisis Perbandingan Biaya Konstruksi}

Dari hasil analisis biaya masing-masing konstruksi di atas untuk aspal beton Rp.

2.994.474.000,00 dan rigid beton Rp. 1.713.571.000,00. Ditinjau dari panjang konstruksi yang dilaksanakan yaitu $2.500 \mathrm{~m}$ atau 2,5 km dan lebar $4 \mathrm{~m}$ dengan tebal 10 $\mathrm{cm}$ untuk aspal beton $\mathrm{AC}-\mathrm{WC}$ dan $\mathrm{AC}-\mathrm{BC}$ serta tebal $15 \mathrm{~cm}$ untuk rigid beton maka diperoleh perbandingan biaya permeter persegi $\left(\mathrm{M}^{2}\right)$ antara aspal beton dengan rigid beton yang terlihat pada tabel berikut:

1 ton aspal beton $=4,3 \mathrm{~m}^{2}$ aspal beton

$1 \mathrm{~m}^{3}$ rigid beton $=6,6 \mathrm{~m}^{2}$ rigid beton

Tabel 4.16 Perbandingan Biaya Konstruksi

\begin{tabular}{|c|c|c|c|}
\hline \multirow[b]{2}{*}{ No } & \multirow[b]{2}{*}{ Jenis Pekerasan } & \multicolumn{2}{|c|}{ Biaya } \\
\hline & & $\begin{array}{c}\text { Biaya Konstruksi } \\
\text { (Rp) }\end{array}$ & $\begin{array}{c}\text { Biaya Per } M^{2} \\
(\text { Rp) }\end{array}$ \\
\hline 1 & Aspal Beton (LPA) & $2.994 .474 .000,00$ & $607.000,00$ \\
\hline 2 & Rigid Beton & $1.713 .571 .000,00$ & $173.000,00$ \\
\hline & Selisih Biaya & 1.280 .903 .000 .00 & $424.000,00$ \\
\hline
\end{tabular}

Sumber: Hasil Analisa 2017

Dengan memperhatikan biaya kontruksi antara aspal beton aspal beton dengan rigid beton maka penggunaan rigid beton dapat menghemat biaya pekerjaan sebesar Rp. 
1.280.903.000.00 terhadap biaya konstruksi aspal beton dan biaya permeter persegi Rp. $424.000,00$.

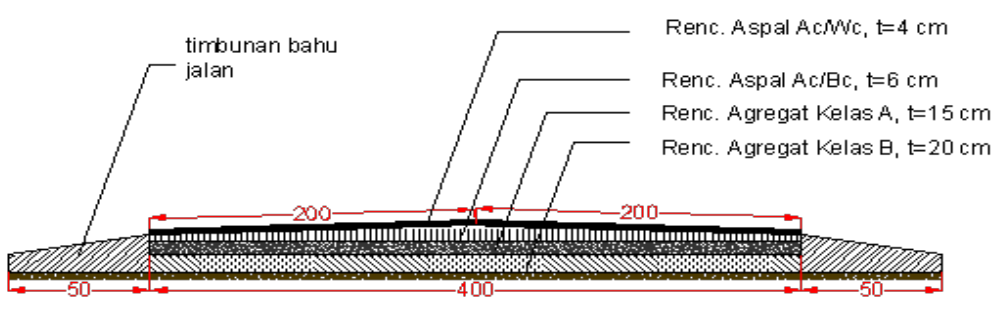

\section{Gambar 4.2. Gambar Penampang Jalan Aspal Beton}

\subsubsection{Metode Pelaksanaan Aspal Beton}
a. Mobilisasi
b. Timbunan Galian Pilihan Dari Sumber Galian
c. Timbunan Pilihan (Diukur Diatas Bak Truk)
d. Lapis Pondasi Agregat Kelas A
e. Lapis Pondasi Agregat Kelas B
f. Lapis Resep Pengikat - Aspal Cair
g. Lapis Perekat - Aspal Cair
h. Laston Lapis Aus (AC-WC)
i. Laston Lapis Antara (AC - BC)

\subsubsection{Metode Pelaksanaan Rigid Beton}
a. Mobilisasi
b. Timbunan Galian Pilihan Dari Sumber Galian
c. Timbunan Pilihan (Diukur Diatas Bak Truk)
d. Beton Mutu Rendah fc'15 MPa

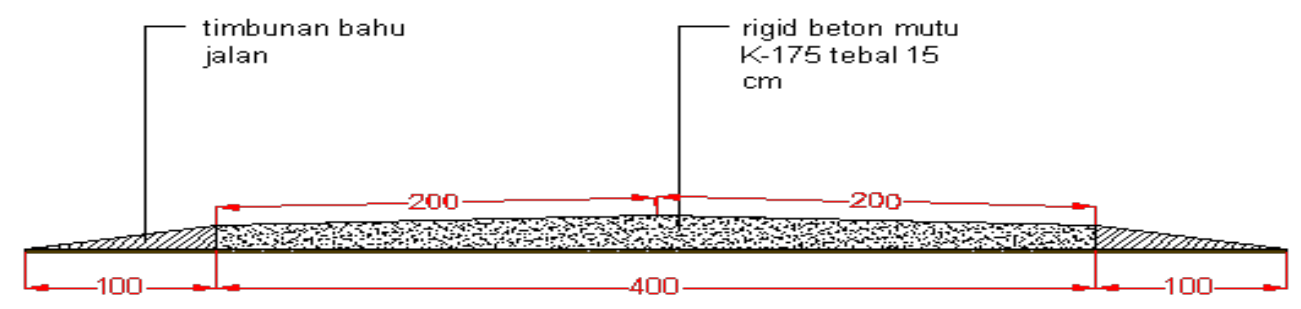

Gambar 4.3. Gambar Penampang Jalan Rigid Beton 


\subsubsection{Perbandingan Metode Pelaksanaan antara Aspal Beton Dengan Rigid Beton}

\section{a. Perbandingan Pelaksanaan}

Ditinjau dari segi pelaksanaan rigid beton lebih efektif karena pekerjaan ini tidak memerlukan banyak item pelaksanaan sedangkan aspal beton memiliki beberapa poin pelaksanaan.

Tabel 4.17 Rekapitulasi Metode Pelaksanaan

\begin{tabular}{|c|l|c|c|}
\hline \multirow{2}{*}{ NO } & \multicolumn{2}{|c|}{ Nama Pekerjaan } & \multicolumn{2}{c|}{ Pekerjaan } \\
\cline { 3 - 4 } & & Aspal Beton & Rigid Beton \\
\hline 1 & Mobilisasi & $\checkmark$ & $\checkmark$ \\
\hline 2 & Timbunan Pilihan Dari Sumber Galian & $\checkmark$ & - \\
\hline 3 & Timbunan Pilihan (Diukur Diatas Bak Truk) & $\checkmark$ & - \\
\hline 4 & Beton Mutu Rendah fc'15 MPa & $\checkmark$ & $\checkmark$ \\
\hline 5 & Lapis Pondasi Agregat Kelas A & $\checkmark$ & - \\
\hline 6 & Lapis Pondasi Agregat Kelas B & $\checkmark$ & - \\
\hline 7 & Lapis Resep Pengikat - Aspal Cair & $\checkmark$ & - \\
\hline 8 & Lapis Perekat - Aspal Cair & $\checkmark$ & - \\
\hline 9 & Laston Lapis Aus (AC-WC) & $\checkmark$ & - \\
\hline 10 & Laston Lapis Antara (AC-BC) & $\checkmark$ & - \\
\hline
\end{tabular}

Sumber: Hasil Analisa 2017

\section{b. Perbandingan Peralatan}

Ditinjau dari segi peralatan yang digunakan rigid beton lebih hemat perlatan dikarenakan alat berat yang dipakai hanya concrete mixer sementara pada aspal beton memerlukan alat berat yang lebih banyak untuk pekerjaannya.

Tabel 4.18 Rekapitulasi Alat Yang Digunakan

\begin{tabular}{|c|l|c|c|}
\hline \multirow{2}{*}{ NO } & \multirow{2}{*}{ Nama Alat } & \multicolumn{2}{|c|}{ Pekerjaan } \\
\cline { 3 - 4 } & & Aspal Beton & Rigid Beton \\
\hline 1 & Concrete Mixer & - & $\checkmark$ \\
\hline 2 & Asphalt Mixing Plant & $\checkmark$ & - \\
\hline 3 & Asphalt Finisher & $\checkmark$ & - \\
\hline 4 & Dump Truck & $\checkmark$ & $\checkmark$ \\
\hline 5 & Truck & $\checkmark$ & - \\
\hline 6 & Tandem Roller & $\checkmark$ & - \\
\hline 7 & Tire Roller & $\checkmark$ & - \\
\hline 8 & Asphalt Sprayer & $\checkmark$ & - \\
\hline 9 & Asphalt Distributor & $\checkmark$ & - \\
\hline 10 & Water Tank Truk & $\checkmark$ & - \\
\hline 11 & Motor Grader & $\checkmark$ & \\
\hline
\end{tabular}

Sumber: Hasil Analisa 2017 


\section{c. Perbandingan Material}

Material yang digunakan untuk rigid beton lebih sedikit dibandingakan dengan aspal beton karena aspal beton memiliki beberapa lapisan perkerasanan dalam pekerjaanya.

Tabel 4.19 Rekapitulasi Material Yang Digunakan

\begin{tabular}{|c|l|c|c|}
\hline \multirow{2}{*}{ NO } & \multicolumn{2}{|c|}{ Nama Pekerjaan } & \multicolumn{2}{c|}{ Pekerjaan } \\
\cline { 3 - 4 } & & Aspal Beton & Rigid Beton \\
\hline 1 & Aspal & $\checkmark$ & - \\
\hline 2 & Miyak Flux & $\checkmark$ & - \\
\hline 3 & Agregat Kasar & $\checkmark$ & $\checkmark$ \\
\hline 4 & Agregat Halus & $\checkmark$ & $\checkmark$ \\
\hline 5 & Semen & - & $\checkmark$ \\
\hline
\end{tabular}

Sumber: Hasil Analisa 2017

\section{d. Perbandingan Waktu Pelaksanaan}

Waktu pelaksanaan untuk aspal beton dilaksanakan dalam 1 bulan 2 minggu sedangkan untuk rigid beton dilaksanakan dalam waktu 2 bulan 3 minggu menurut waktu pelaksanaan yang telah dihitung dari hasil masing-masing perkerasan dengan volume yang sama sehingga dapat dikatakan perkerasan jalan aspal beton lebih cepat selesai dalam hal waktu pelaksanaan disbanding dengan aspal beton dengan selisih waktu 1 bulan 6 hari kerja.

Tabel 4.11 Perbandingan Waktu Pelaksanaan

\begin{tabular}{|c|l|r|r|}
\hline No & \multicolumn{1}{|c|}{ Jenis Pekerasan } & $\begin{array}{c}\text { Biaya Per } \mathbf{M}^{2} \\
\text { (Rp) }\end{array}$ & $\begin{array}{c}\text { Waktu Pekerjaan } \\
\text { Per } \mathbf{M}^{2} \text { (Hari) }\end{array}$ \\
\hline 1 & Aspal Beton (LPA) & $607.000,00$ & 0,009 \\
\hline 2 & Rigid Beton & $173.000,00$ & 0,0081 \\
\hline
\end{tabular}

Sumber: Hasil Analisis 2017

\section{BAB V}

\section{KESIMPULAN DAN SARAN}

\subsection{Kesimpulan}

Berdasarakan hasil penelitian dan analisis data, dari penelitian ini dapat disimpulkan sebagai berikutt:

1. Dengan memperhatikan biaya kontruksi antara aspal beton dengan rigid beton maka penggunaan rigid beton dapat menghemat biaya pekerjaan sebesar Rp. 
1.280.903.000.00 terhadap biaya konstruksi aspal beton dengan panjang jalan yang sama yaitu $2.500 \mathrm{~m}$ atau $2,5 \mathrm{~km}$.

2. Dari segi metode pelaksanaan terjadi perbedaan yang mendasar yaitu bila rigid beton tidak perlu dipadatkan untuk lapis permukaan, sedangkan aspal beton harus melalui tahap pemadatan untuk lapis permukaan dan untuk alat-alat yang digunakan untuk pekerjaaan kontsruksi, dari segi material rigid beton lebih sedikit dibandingkan dengan aspal beton, sedangkan dari segi waktu pelaksanaan aspal beton hanya 1 bulan 2 minggu pekerjaan di bandingkan rigid beton yang lebih lama pelaksanaan pekerjaan sekitar 2 bulan 3 minggu pekerjaan.

3. Ditinjau dari faktor biaya, metode pelaksanaan, alat-alat yang digunakan, material dan waktu pelaksanaan maka rigid beton dapat dikatakan lebih efisien dari aspal beton.

\subsection{Saran}

Beberapa saran dan rekomendasi yang mengacu dari analisa dan pembahasan penelitian ini antara lain sebagai berikut :

1. Perlu diadakan penelitian lebih lanjut untuk bebarapa mutu beton yang berbeda selain mutu beton K-175 yang digunakan dalam penulisan ini.

2. Perlu adanya penelitian lebih lanjut untuk analisa biaya dan metode pelaksanaan apabila rigid beton menggunakan tulangan pada perkerjaannya.

\section{DAFTAR PUSTAKA}

AASHTO, Standard Specifications for Transfortation Materials and Methods of Sampling and Testing, Part I, Specifications, Nineteenth Edition, Washington D.C. 1998 Amri Sjafey, Teknologi Beton A-Z, Jakarta, 2005.

Dangzt Iman, Jenis- Jenis Aspal, Artikel Civil Engineering, 2014.

Departemen PU Direktorat Jendral Bina Marga. (1986). Perkerasan Kaku (Rigid Pavement). Yayasan Badan Penerbit PU. Jakarta.

Departemen Pekerjaan Umum Dan Perumahan Rakyat, Pedoman Perancangan Dan Pelaksanaan Lapis Penutup Dengan Bubur Aspal Emulsi , 2015.

Ditjen Bina Marga, Panduan Analisa Harga Satuan, Departemen Pekerjaan Umum, Jakarta, 2010.

Edward G. Nawy, (alih bahasa : Bambang Suryoatmono), Beton Bertulang : Suatu Pendekatan Dasar, PT. Eresco, Bandung, 1996.

Fahmi Adam, Spektek Metode Pelaksanaan Jalan Aspal, 2013.

Parea Rusan Rangan, Implikasi Kinerja Proyek Gedung Dengan Metode Least Cost Analysis

Http://www.MahakaryaEngineering.co.id/aspal/beton/.html; internet; accessed 20 juli 2016.

Ibrahim, H. B. : Rencana Dan Estimate Real Of Coast, Penerbit PT Bumi Aksara, Jakarta, 2003.

Machfud Hamdan, Metode Pekerjaan Jalan Beton, Academia, 2014. 
Mashuri, Karakteristik Aspal sebagai Bahan Pengikat, Jurnal Smartek, 2010.

Mulyono Tri. Teknologi Beton. Penerbit Andi Yogyakarta, 2005.

Murdock, L. J. D. Sc ; Brook K.M, Bahan dan Praktek Beton, Edisi Ke Empat. Penerbit Erlangga, Jakarta, 1991.

Oglesby, Clarkson H and R Gary Hicks. Teknik Jalan Raya, Edisi ke empat Jilid 2. Jakarta: Erlangga. 1996.

SNI 03-1737, Tata Cara Pelaksanaan Lapis Aspal Beton (Laston) Untuk Jalan Raya, 1989.

Soeharto, Iman ; Manajemen Konstruksi Dari Konseptual Sampai Oprasional, Jakarta, Erlangga, 1997.

Sukirman Silvia, Buku Besar Laboratorium Rekayasa Jalan, Jurusan Teknik Sipil Institut Teknologi Bandung, 2003.

Tjokrodimuljo Kardiyono, Teknologi Beton, Nafiri, Yogyakarta, 1996. 